\title{
Resolving the Complexity of Spatial Lipidomics Using MALDI TIMS Imaging Mass Spectrometry
}

\author{
Katerina V. Djambazova1,2, Dustin R. Klein2,3, Lukasz G. Migas4, Elizabeth K. Neumann2,3, Emilio S. \\ Rivera2,3, Raf Van de Plas4, Richard M. Caprioli1-3,5,6 and Jeffrey M. Spraggins1-3*. \\ 1Department of Chemistry, Vanderbilt University, 7330 Stevenson Center, Station B 351822, Nashville, TN 37235, USA \\ 2Mass Spectrometry Research Center, Vanderbilt University, 46521 st Ave S \#9160, Nashville, TN 37235, USA \\ 3Department of Biochemistry, Vanderbilt University, 607 Light Hall, Nashville, TN 37205, USA \\ 4Delft Center for Systems and Control, Delft University of Technology, 2628 CD Delft, The Netherlands \\ 5Department of Pharmacology, Vanderbilt University, 2220 Pierce Avenue, Nashville, TN 37232, USA \\ 6Department of Medicine, Vanderbilt University, $46521_{\text {st }}$ Ave S \#9160, Nashville, TN 37235, USA
}

KEYWORDS. Imaging mass spectrometry, Matrix-assisted laser desorption/ionization, Trapped ion mobility spectrometry, Ion mobility mass spectrometry, Lipidomics

\begin{abstract}
Lipids are a structurally diverse class of molecules with important biological functions including cellular signaling and energy storage. Matrix-assisted laser desorption/ionization (MALDI) imaging mass spectrometry (IMS) allows for direct mapping of biomolecules in tissue. Fully characterizing the structural diversity of lipids remains a challenge due to the presence of isobaric and isomeric species, which greatly complicates data interpretation when only $\mathrm{m} / \mathrm{z}$ information is available. Integrating ion mobility separations aids in deconvoluting these complex mixtures and addressing the challenges of lipid IMS. Here we demonstrate that a MALDI quadrupole time-of-flight (Q-TOF) mass spectrometer with trapped ion mobility spectrometry (TIMS) enables a $>250 \%$ increase in the peak capacity during IMS experiments. MALDI TIMS-MS separation of lipid isomer standards, including $s n$ backbone isomers, acyl chain isomers, as well as double bond position and stereo- isomers are demonstrated. As a proof-of-concept, in situ separation and imaging of lipid isomers with distinct spatial distributions was performed using tissue sections from a wholebody mouse pup.
\end{abstract}

Lipids are crucial components of cellular membranes with essential functions in cellular structure, signaling, energy storage, and homeostasis.1-4 They are structurally diverse molecules, with many having the same nominal mass and some having the same exact mass. Developing more comprehensive ways of characterizing these complex mixtures in tissue is important, as even subtle structural differences can have significant biological implications. Mass spectrometry (MS) is a powerful tool for lipid analysis with common ex vivo approaches utilizing electrospray ionization (ESI) and either direct infusion of lipid extracts or separations via liquid chromatography, neither of which retain spatial information of the analyte in tissue.3,5 In contrast, imaging mass spectrometry (IMS), which analyzes biomolecules in situ, enables highly specific mass analysis while retaining analyte spatial information.6 Matrix-assisted laser desorption/ionization (MALDI), one of the most commonly used ionization techniques for IMS, permits visualization of lipids7,8, metabolites9,10, glycans11,12, peptides14, and proteins15,16. In a typical MALDI IMS experiment, tissues are thinly sectioned, mounted on a conductive glass slide, and coated with an UVabsorbing matrix. Desorption and ionization is facilitated by laser ablation at specific positions on the tissue surface. An individual mass spectrum is generated at each position (pixel), and molecular images are generated by plotting the ion intensity as a heat map across all the pixels sampled on the tissue. 16 The spatial resolution of these chemical images is defined by the laser ablation area on the tissue and the spacing between the pixels (pitch).

The structural diversity of lipids in tissues can often be underrepresented during MALDI IMS experiments owing to the presence of isobars and isomers that cannot be distinguished by their measured $\mathrm{m} / \mathrm{z}$ alone. High resolving power and high mass accuracy instrumentation, including Fourier transform ion cyclotron resonance (FT-ICR) and Orbitrap mass analyzers, have been critical in enabling both lipid identification at the sum composition level, as defined by Liebisch et al2, and isobar differentiation.17,18 However, structural isomers with identical masses cannot be separated simply by high mass resolving power instruments. In these cases, ion images of single $\mathrm{m} / \mathrm{z}$ values may depict composites of multiple lipid species. Tandem MS $\left(\mathrm{MS}_{\mathrm{n}}\right)$ has been used to reveal distributions of isomeric lipids in situ. Novel MS techniques, including low-energy collision-induced dissociation 19 with Paternò-Büchi derivatization 20 , ozone-induced dissociation 21 , and ultraviolet photodissociation22, have revealed differential localization of double-bond positional and $s n$-positional isomers. While $\mathrm{MS}_{\mathrm{n}}$ 
techniques provide a higher degree of structural characterization, they are highly targeted.23 In addition, while integration of online chromatographic separation with direct tissue sampling can increase the specificity of an IMS experiment, this setup typically requires lengthy acquisition times.24,25 Alternatively, chromatographic techniques can be applied to serial tissue sections to further increase the specificity of an IMS experiment.

Ion mobility enables gas-phase separation of molecules according to their shape, size and charge on timescales ( $\mu \mathrm{s}-\mathrm{ms}$ ) that are compatible with typical IMS experiments. Ion mobility separation techniques include drift tube ion mobility spectrometry (DTIMS)26,27, traveling wave ion mobility spectrometry (TWIMS)28,29, field asymmetric ion mobility spectrometry (FAIMS) $30-32$, and trapped ion mobility spectrometry (TIMS) 33,34 . DTIMS and TWIMS are operated under lower pressure regimes and have typically been coupled to time-of-flight (TOF) mass spectrometers. Mobility trendlines generated during DTIMS and TWIMS experiments have been beneficial for identifying classes and subclasses of lipids, and have also enabled increases in signal-to-noise measurements.27,28 DTIMS and TWIMS have both been used to separate ESI-generated lipid isomers, including sn-positional, double bond positional, and stereochemical isomers ( $\mathrm{R}$ versus S).35-37 Furthermore, both TWIMS and DTIMS have previously been utilized on instruments capable of imaging mass spectrometry.38,39 Recent developments in TWIMS technologies have led to the development of structures for lossless ion manipulations (SLIM) 40,41 capable of highresolution separations of many lipid isomers.38 Although SLIM shows promise for elucidating subtle structural differences, it has only been coupled to liquid surface probes and has not yet been integrated with a MALDI IMS setup.45 FAIMS devices do not require low pressures and can be integrated in a variety of mass spectrometers. 46 With the exception of a higher resolution planar-FAIMS device44, most FAIMS devices operate at relatively low resolving power and are used to filter specific classes or subclasses of lipids.36 For example, shotgun lipidomic studies with FAIMS have been successful in lipid class separations 36,47 , and Lintonen et al. have shown the use of FAIMS for the construction of lipid class trendlines.48 Similar to DTIMS and TWIMS, FAIMS has also been coupled to IMS platforms. For example, Feider et al. have demonstrated improved detection and imaging of cardiolipins in rat brain with the use of FAIMS and desorption electrospray ionization.49

Recently, TIMS integration with IMS has shown great potential for high-resolution separations.50 TIMS platforms are capable of resolving powers $>200$ in $50-500$ ms.34,51-53 Briefly, TIMS is performed in the first vacuum stage of the mass spectrometer in an augmented ion funnel. An electric field gradient (EFG) is applied to the ion tunnel to trap ions against a carrier gas and separate them based on mobility. Following ion trapping, the EFG is gradually reduced to sequentially elute ions with ascending mobilities.33,52 The voltage range $\left(\Delta \mathrm{V}_{\text {ramp }}\right)$ and ramp time (tramp) dictate the scan rate $\left(S_{r}=\Delta V_{\text {ramp }} / t_{\text {ramp }}\right) 54$, with slower scan rates resulting in higher resolution separations. While a MALDI TIMS-MS platform has successfully been used to separate and spatially map lipid species that overlap in $\mathrm{m} / \mathrm{z}$ space, a full assessment of the effect of TIMS on peak capacity and isomer separation in an imaging context has not yet been demonstrated.50,55 In addition, the ability of TIMS to resolve isomeric lipids via liquid chromatography-TIMS-MS suggest it has the capability to resolve isomeric lipids in situ.50

Here we present the use of the TIMS technology for increased peak capacity and deconvolution of complex lipid mixtures in an imaging context. The high-resolution separation of MALDIgenerated lipid isomer standards is demonstrated, followed by an in situ assessment of lipid peak capacity using TIMS-IMS and visualization of lipid isomers in a full-body mouse pup tissue. These data provide the foundation for maximizing sensitivity and specificity of lipid imaging experiments on TIMS-based MALDI platforms.

\section{METHODS}

Materials: 1,5-diaminonaphthalene (DAN) and 2',5'dihydroxyacetophenone (DHA) were purchased from SigmaAldrich (St. Louis, MO, USA). HPLC-grade acetonitrile, methanol, ethanol, chloroform, and tetrahydrofuran (THF) were purchased from Fisher Scientific (Pittsburgh, PA, USA). Lipid standards were purchased from Avanti Polar Lipids (Alabaster, AL, US).

Sample Preparation: For tissue preparation, one-week old C57BL/6 control mouse pup was snap frozen at $-80{ }_{\circ} \mathrm{C}$, shaved

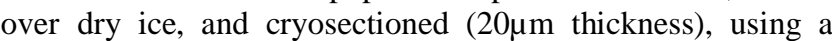
CM3050 S cryostat (Leica Biosystems, Wetzlar, Germany). The tissue was thaw-mounted onto conductive indium tin oxide coated glass slides (Delta Technologies, Loveland, CO, USA). The sample was placed on a heated metal block $(75 \circ \mathrm{C})$ and coated with a $15 \mathrm{mg} / \mathrm{mL}$ solution of DAN dissolved in THF using a TM Sprayer (HTX Technologies, LLC, Chapel Hill, $\mathrm{NC}$, USA) $(0.05 \mathrm{~mL} / \mathrm{hr}, 5$ passes, $0 \mathrm{sec}$ drying time, 40 ○C spray nozzle). For lipid standard analysis, the standards (in chloroform) were aliquoted in vials $(5 \mathrm{mg} / \mathrm{mL})$, dried down with nitrogen gas, and dissolved in $80 \%$ methanol for a final concentration of $1.0 \mathrm{mg} / \mathrm{mL}$. The aliquots were then mixed with DHA matrix, dissolved in $90 \%$ acetonitrile to a final lipid concentration of $0.2 \mathrm{mg} / \mathrm{mL}$. The mixtures were spotted on a polished steel target - MTP AnchorChip (Bruker Daltonik, Bremen, Germany).

MALDI TIMS-IMS: All experiments were carried out on a prototype timsTOF fleX mass spectrometer (Bruker Daltonik, Bremen, Germany).50 Images were acquired in TIMS mode of operation with an ion transfer time of $100 \mu \mathrm{s}$, pre-pulse storage time of $8 \mu \mathrm{s}$, a collision RF of $2000 \mathrm{Vpp}$, a TIMS funnel 1 (accumulation) RF of $450 \mathrm{Vpp}$, a TIMS funnel $2 \mathrm{RF}$ (analysis) of $400 \mathrm{Vpp}$, a multipole RF of $400 \mathrm{Vpp}$, and a collision cell entrance (in) voltage of $300 \mathrm{~V}$. Tissue imaging data (196514 pixels) were collected at $50 \mu \mathrm{m}$ spatial resolution with beam scan on $(46 \mu \mathrm{m})$, using 200 shots per pixel and $48 \%$ laser power. Data were collected in positive ion mode from $\mathrm{m} / \mathrm{z}, 50-1500$. The TIMS EFG scan time was set to $650 \mathrm{~ms}$, with reduced mobility $\left(1 / \mathrm{K}_{0}\right)$ range of $1.370-1.520 \mathrm{Vs} / \mathrm{cm}_{2}\left(\mathrm{~S}_{\mathrm{r}}=0.03 \mathrm{~V} / \mathrm{ms}\right)$. TIMS imaging data was visualized using custom in-house developed software. Lipid identifications were determined with high mass accuracy and LIPIDMAPS lipidomics gateway (lipidmaps.org56,57).

Lipid standards data were acquired in TIMS mode of operation with specific tuning of TIMS ramp time, mobility range, and scan rate for each of the analyzed standards. Data were acquired 
at $20 \mu \mathrm{m}$ spatial resolution with $\sim 25 \%$ laser power at $10 \mathrm{kHz}$, 200 shots per pixel, and 200 pixels per sample. Based on the laser repetition rate and the number of shots per pixel, the ion accumulation time per pixel was $20 \mathrm{~ms}$. For all isomer standard experiments, the ramp time (tramp) was kept constant $(650 \mathrm{~ms})$, and the mobility range was manipulated such that the voltage change $\left(\Delta V_{\text {ramp }}\right)$ and therefore scan rate $\left(\mathrm{S}_{\mathrm{r}}=\sim 0.01 \mathrm{~V} / \mathrm{ms}\right)$ was kept constant across experiments. A full list of the experimental parameters is included in Table S1.

MALDI FT-ICR IMS: Whole-body mouse pup tissue data were acquired using a 15T MALDI FT-ICR mass spectrometer (Bruker Daltonics, Billerica, MA, USA). The images were generated with the "small" laser setting $\sim 50 \mu \mathrm{m}$, with a spatial resolution of $150 \mu \mathrm{m}$. The data was collected with 300 laser shots per pixels at $46 \%$ laser power. The recorded mass spectrum had a $m / z$ range of 460-1500 with a transient length of $4.2 \mathrm{~s}$, resulting in a resolving power of $\sim 600000$ at $\mathrm{m} / \mathrm{z} 760$.

Data Processing: The mouse pup data was exported into a custom binary format optimized for storage and speed of analysis of the ion mobility-IMS data collection. Each frame/pixel contains between 10,000 - 100,000 centroid peaks that span the acquisition range of $\mathrm{m} / z 50-1500$ and $1 / \mathrm{K}_{0} 1.370$ $1.520 \mathrm{Vs} / \mathrm{cm}_{2}$ with 400,577 and 5857 bins in the MS and ion mobility-dimensions, respectively. The processing pipeline requires common $\mathrm{m} / \mathrm{z}$ and $1 / \mathrm{K}_{0}$ axes, hence individual centroid peaks were inserted at their correct bin position along the MS and ion mobility-dimensions; missing values were set to zero. Following the conversion process, a mean mass spectrum of the entire dataset was generated and peak-picked. A total of $\sim 400$ most intense ions were then selected and extracted to generate ion mobility rich ion images. Each of the extracted ion mobilityion images was peak-picked (in the ion mobility-dimension) and automatically fitted with Gaussian-distributions to identify single and multi-conformational species. Ion mobility-selected ion images were then visualized to examine the conformationalspecific localization in the spatial domain.

Peak capacity refers to the number of detectable features. A peak in the $\mathrm{m} / \mathrm{z}$ domain corresponds to a spectral feature for which the area under the curve (AUC) was calculated and the full-width at half-maximum (FWHM) determined. An in-house developed peak picker was used to create a list of spectral features found in the average mass spectrum which were then filtered based on the minimal intensity $(>0.1 \%$ of the base peak). In the TIMS dimension, a peak corresponds to a feature which was fitted with a single Gaussian curve allowing for the calculation of the AUC and FWHM. Ion mobility profiles containing multiple conformations were fitted with multiple Gaussians peaks to represent the profile, as a single $m / z$ species can have several IM features.

\section{RESULTS AND DISCUSSION}

TIMS Peak Capacity: Direct sampling of lipids from tissue by imaging mass spectrometry produces complex mass spectra. To assess the advantage of incorporating TIMS into an IMS workflow, spectral peak capacity (i.e. the number of detectable features) was determined for an average spectrum of a wholebody mouse pup tissue image. Peak capacity is determined by peak picking the data to identify the number of unique mass spectral features with and without incorporating TIMS data.
When the TIMS dimension is incorporated, the peak capacity is determined as the number of unique mass spectral and associated mobility features. The average mass spectrum from $m / z, 680-880$ with no ion mobility separation shown in Figure 1A has a peak capacity of 247 . Over the same $m / z$ range, with a $650 \mathrm{~ms}$ TIMS separation, the peak capacity increases to 916 . Figure 1B provides a heat map representation of the ion mobility-MS data. Integrating ion mobility into the MALDI IMS workflow, therefore, provides a $>250 \%$ increase in the number of species detected for lipid IMS experiments.

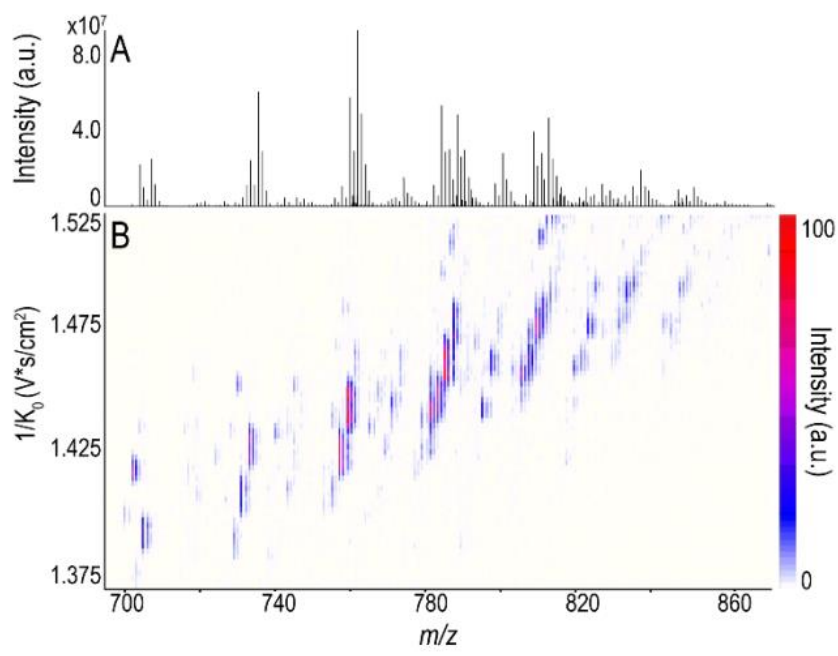

Figure 1: Average mass spectrum (A) and ion mobility heat map (B) generated for average whole-body mouse pup data highlight the presence of multiple isobaric and isomeric species. The diversity of ions observed in the heat map for each $\mathrm{m} / \mathrm{z}$ highlight the complexity of the data and demonstrate the increased peak capacity by incorporating the TIMS separation dimension. The mass spectrum ranges include $\mathrm{m} / \mathrm{z}$ values $680-880$ and the heat map incorporates $1 / \mathrm{K}_{0}$ values $1.375-1.500$.

The increased peak capacity afforded by TIMS results from the separation of isobaric and isomeric species that otherwise overlap in the $\mathrm{m} / \mathrm{z}$ dimension. A well-documented example of isobaric interference that occurs with lipid analysis results from overlap of an M+2 isotopologue of one species with the monoisotopic (M) peak of another lipid with one less double bond. This 'double bond ambiguity' gives rise to a mass difference of 0.00895 Da.58 Peak overlap that results from unresolved isotopic distributions can lead to artificially high mass errors that preclude lipid identification.58,59 While TOF instruments generally are not able to resolve peaks resulting from lipid double bond ambiguity, the added dimension of ion mobility allows for gas phase separations that help address this spectral complexity. Figure 2 provides an example of how TIMS can resolve overlapping isotopes for the ion of $\mathrm{m} / \mathrm{z}$ 848.55 . With a mobility separation time of $650 \mathrm{~ms}$, the ion of $\mathrm{m} / \mathrm{z} 848.55$ resolves into two mobility peaks at $1 / \mathrm{K}_{0} 1.485-$ 1.499 and $1 / \mathrm{K}_{0} 1.468-1.485$. Figure $2 \mathrm{~A}$ shows the composite ion image combining the mobility separated species for $\mathrm{m} / \mathrm{z}$ 848.55. Figures $\mathbf{2 B}$ and $\mathbf{2 C}$ show the individual ion images for $1 / \mathrm{K}_{0} 1.485-1.499$ and $1 / \mathrm{K}_{0} 1.468-1.485$, respectively, each of which localizes to distinct regions of the tissue. For example, $1 / \mathrm{K}_{0} 1.485-1.499$ is found at higher abundance in the brain and with more distinct localization to the intestinal walls as compared to $1 / \mathrm{K}_{0} 1.468$ - 1.485 , which shows unique 
localization in the adipose tissue. Figure 2D shows the ion image of $m / z 846.54$ for the mobility range of $1 / \mathrm{K}_{0} 1.468-$ 1.485 , which, by comparison, localizes to the same regions of tissue as $m / z, 848.55$ for the mobility range of $1 / \mathrm{K}_{0} 1.468-$ 1.485. Considering the intact mass measurements and differences in spatial localizations, the species at $\mathrm{m} / \mathrm{z} 848.55$ with a mobility elution time of $1.485-1.499$ likely corresponds to the monoisotopic peak of phosphatidylcholine (PC) [PC(38:4)+K $]_{+}$, while the species of $m / z 848.55$ with a mobility elution time of $1.468-1.485$ corresponds to the $M+2$ peak of $[\mathrm{PC}(38: 5)+\mathrm{K}]+$. Without a mobility separation, $\mathrm{m} / \mathrm{z} 848.55$ would likely be assigned solely as the higher intensity $[\mathrm{PC}(38: 4)+\mathrm{K}]_{+}$and the generated ion image would provide a skewed representation of its distribution throughout the tissue.
Separation of MALDI-generated Lipid Isomer Standards: Isomers have the same chemical formulas (identical $\mathrm{m} / \mathrm{z}$ values), and therefore cannot be separated in $\mathrm{m} / \mathrm{z}$, space. Gasphase separations prior to MS analysis have been successful in resolving isomeric species. Here MALDI TIMS isomer separations were evaluated in both positive and negative ion mode. The performance was assessed using standards including isomers with differences in $s n$-position, acyl chain composition, double bond position, and double bond stereochemistry (Figure S1). These standards have previously been characterized using ESI techniques in combination with TIMS, as well as other separation techniques.37,60 MALDI TIMS analyses, however, lay the groundwork for isomer differentiation within a molecular imaging context. The mass spectra of the individual standards can be found in Figures S2 and S3. Extracted ion

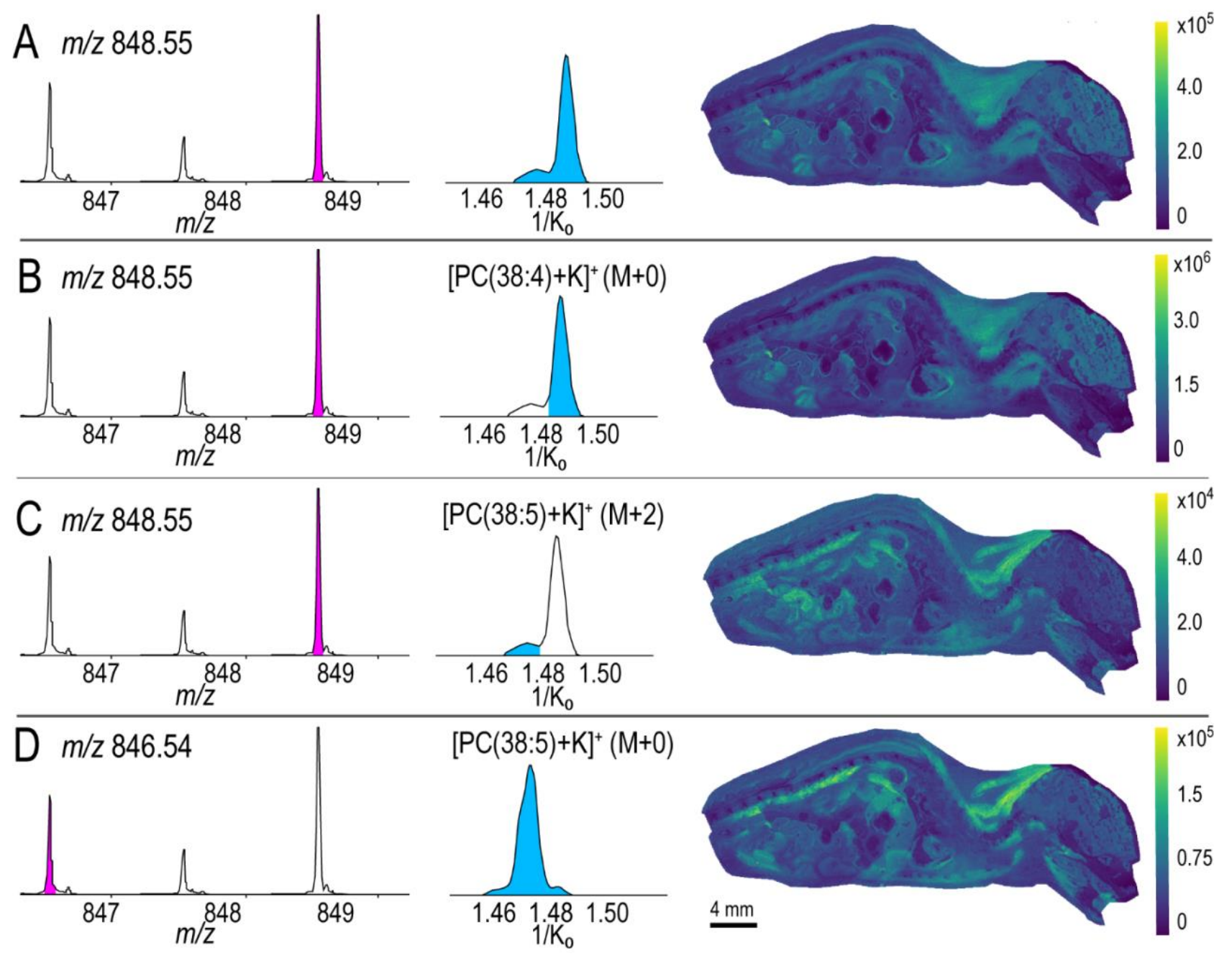

Figure 2: The added dimension of ion mobility helps address spectral ambiguities to show how the double bond ambiguity is resolved for the ion of $m / z$ 848.55. The ion of $m / z 848.55$ resolves into two peaks at $1 / \mathrm{K}_{0} 1.485-1.499$ and $1 / \mathrm{K}_{0} 1.468-1.485$ (A). A composite image of the two peaks (A) and individual ion images for $1 / \mathrm{K}_{0} 1.485-1.499$ (B) and 1/K0 1.4768 - 1.485 (C) highlight differences in their spatial distributions. The ion image of $m / z 846.54\left(1 / \mathrm{K}_{0} 1.468-1.485\right)$ (D) localizes to the same regions as $\mathrm{m} / z$ 868.55 for the mobility range of $1 / \mathrm{K}_{0} 1.468-1.485$ (C). The species of $m / z 848.55$ with $1 / \mathrm{K}_{0} 1.485-1.499$, likely corresponds to the $\mathrm{M}+0$ (monoisotopic) peak of $[\mathrm{PC}(38: 4)+\mathrm{K}]_{+}$, while the species of $\mathrm{m} / z 848.55$ with $1 / \mathrm{K}_{0} 1.468-1.485$ corresponds to the $\mathrm{M}+2$ peak of $[\mathrm{PC}(38: 5)+\mathrm{K}]+$.

mobilograms were generated for each standard as well as for mixtures of isomeric standards. Both ion mobility resolving 
power $(\mathrm{R})$, and resolution $(\mathrm{r})$, defined as $\mathrm{R}=\left(1 / \mathrm{K}_{0}\right) / \mathrm{w}$ and $\mathrm{r}=$ $1.18 *\left(1 / \mathrm{K}_{0,2}-1 / \mathrm{K}_{0,1}\right) /\left(\mathrm{W}_{1}+\mathrm{w}_{2}\right)$, where $\mathrm{w}$ is the full peak at half-maximum.

Sn-position

Subtle differences in glycerophospholipid structure, including differences in acyl chain positions, can have dramatic effects on biological function. A unique case of $s n$-positional isomers is bis(monoacylglycerol)phosphates (BMPs) and phosphatidylglycerols (PGs). In contrast to PGs, where both acyl chains are connected to the glycerol backbone, BMPs have one acyl chain connected at the $s n-1$ position on the glycerol backbone and a second acyl chain connected to the $s n-1$ ' position of the glycerol headgroup, resulting in an unusual sn1:sn-1' orientation.37,61 Differentiation of BMPs and PGs is important, as both are present in mammalian cells, but differ in their biological roles and cell locations. BMP lipids have been found in the endosomal and lysosomal compartments of the cell and have been associated with Niemann-Pick disease, an endosomal/lysosomal storage disease 62,63 . PGs, on the other hand, are thought to have antiviral properties, inhibiting viral proliferation in the lungs including respiratory syncytial virus.61,64

Sn-positional isomers are particularly challenging to characterize as collision-based tandem mass spectrometry methods produce spectra with only differences in ion abundances, i.e, non-unique identifying ions.61 To evaluate MALDI TIMS as a platform to separate PG and BMP isomers, mobility data was collected for the standards PG (14:0/14:0) and BMP (14:0/14:0) (Figure 3A). Standards were first analyzed individually to determine mobility values. The MS1 spectrum for each standard contains a predominant ion of $\mathrm{m} / z$ 665.49 , corresponding to the $[\mathrm{M}-\mathrm{H}]$ - species for each lipid. The measured $1 / \mathrm{K}_{0}$ values were 1.268 and 1.283 for PG (14:0/14:0) and BMP (14:0/14:0), respectively. The difference in backbone orientation results in an increased distance between the acyl chains and consequently an

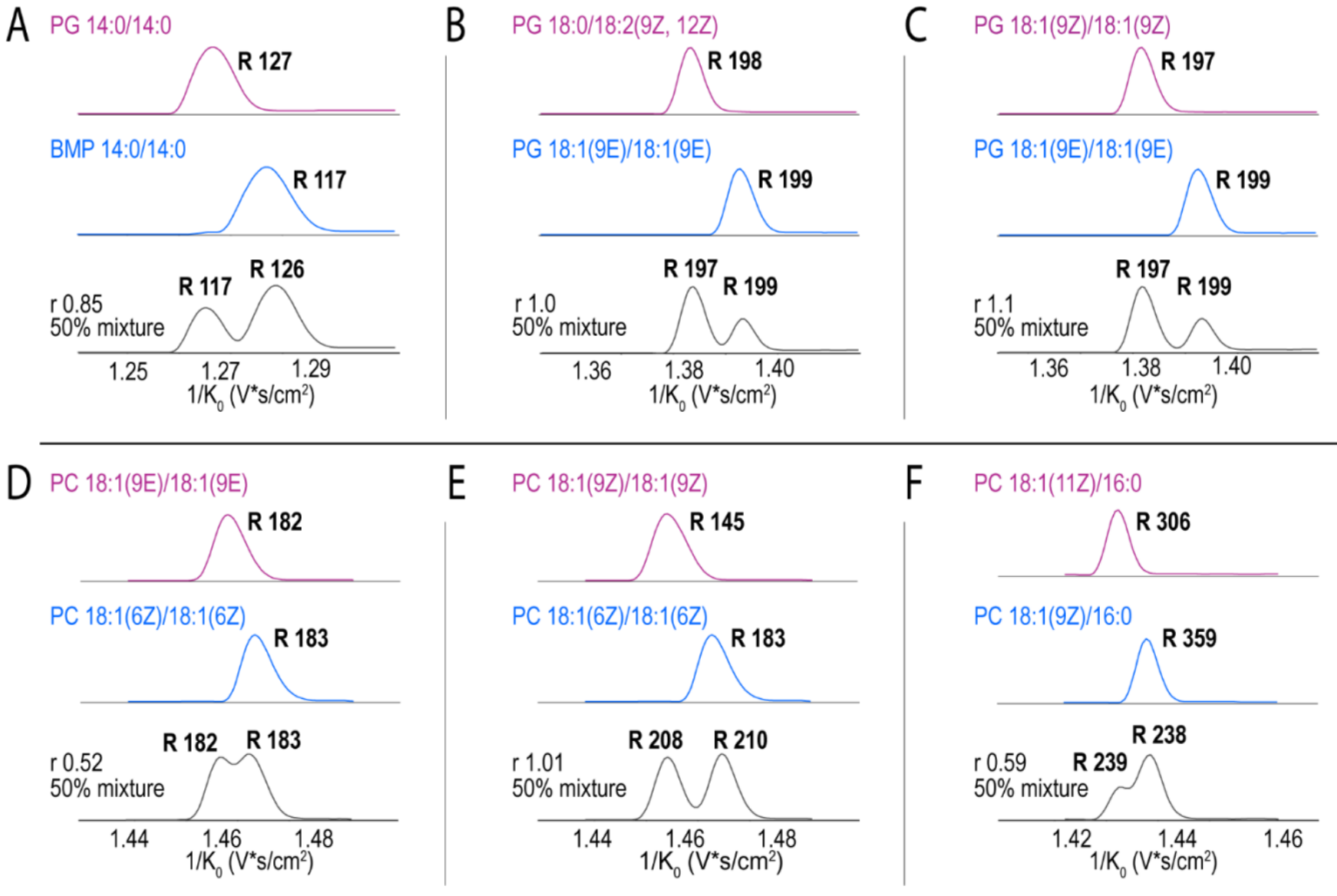

Figure 3: Extracted ion mobilograms of MALDI-generated ions of isomeric lipid standards are shown for both negative (A-C) and positive ionization mode (D-F). Negative ionization mode analysis of $s n$-backbone isomers PG (14:0/14:0) and BMP (14:0/14:0) ([M-H]- , $m / z$ 665.49) (A); Analysis of double bond position and stereo- isomers - PG (18:0/18:2 (9Z, 12Z)) and PG (18:1/18:1 (9E)) (B) and PG (18:1(9Z)/18:1 (9Z)) and PG ((18:1(9E)/18:1(9E)) ([M-H]- , $m / z$ 773.53) (C). Positive ion mode analysis of double bond position and stereo- isomers - PC (18:1(9E)/18:1(9E)) and PC (18:1(6Z)/18:1(6Z)) (D) and PC (18:1(9Z)/18:1(9Z)) and $\mathrm{PC}(18: 1(6 \mathrm{Z}) / 18: 1(6 \mathrm{Z}))\left([\mathrm{M}+\mathrm{Na}]_{+}, \mathrm{m} / z\right.$ 808.57) $(\mathbf{E})$, as well as PC $(18: 1(11 \mathrm{Z}) / 16: 0)$ and PC18:1(9Z)/16:0) $\left([\mathrm{M}+\mathrm{Na}]_{+}, \mathrm{m} / z\right.$. 782.56) (F). Resolving power (R) is listed where appropriate.

increased difference in collisional cross section between BMP and PG.37 A 1:1 mixture was analyzed to evaluate the separation of the isomers. An extracted ion mobilogram was generated for the deprotonated species $(\mathrm{m} / \mathrm{z}, 665.49)$, and two peaks could be resolved in the mobilogram (1.270 and 1.282). The mobilogram of the mixture shows separation of the two species with a resolution of 0.84 . Based on the $1 / \mathrm{K}_{0}$ values, our results indicate that the PG has a more compact structure than the BMP, which is consistent with previous studies.37,61 
Acyl Chain Composition, Double Bond Position and Double Bond Stereochemistry

The biophysical effects of acyl chain compositions and the positions and stereochemistry (cis (Z) vs trans (E)) of double bonds in lipid acyl chains are well documented.65,66 The thickness and fluidity of biological membranes are affected by lipid double bond stereochemistry, as well as acyl chain length.35,37 Specifically, shorter acyl chains and cis- double bonds result in thinner, more fluidic membranes .67 Lipids with trans double bonds are known to cause changes in membrane function and inhibition of lipid enzymatic pathways35. Differences in double bond position, on the other hand, have been linked to the development of various diseases, including cancer and type 2 diabetes, 68 and have been known to influence lipid-protein binding. 69 To assess the separation capabilities of MALDI TIMS for isomers in both negative and positive ionization mode, lipids with differences in the acyl chain composition, double bond position, double bond stereochemistry, and combinations of composition, position, and stereochemistry were examined. First, MALDI TIMS was performed in negative ionization mode for the deprotonated ions of PG (18:1(9E)/18:1(9E)) and PG (18:0/18:2(9Z,12Z)) (Figure 3B). Both lipids have two unsaturations: $P G$ $(18: 0 / 18: 2(9 Z, 12 Z))$ has two double bonds on the same acyl chain in cis stereochemistry and PG (18:1/18:1(9E)) has a single unsaturation on each chain with trans stereochemistry; these lipid standards differ in acyl chain composition, double bond position, and double bond stereochemistry. The mass spectrum of each standard was dominated by the $[\mathrm{M}-\mathrm{H}]$ - ion at $m / z$ 773.53. The measured $1 / \mathrm{K}_{0}$ values for $\mathrm{PG}$ (18:1(9E)/18:1(9E)) and PG (18:0/18:2(9Z,12Z) were 1.394 and 1.383 , respectively. The lower $1 / \mathrm{K}_{0}$ value for $P G$ (18:0/18:2(9Z,12Z) suggests it assumes a more compact gasphase structure. A mixture of the two standards shows partial separation $(r=1.0)$, suggesting that isomers with differences in acyl chain composition, double bond position, and stereochemistry could be resolved in situ. To further test the separation capabilities for more subtle differences in structures, mobility data were collected for PG $(18: 1(9 \mathrm{E}) / 18: 1(9 \mathrm{E}))$ and PG (18:1(9Z)/18:1(9Z)), where the only difference is double bond stereochemistry. Extracted ion mobilograms of the deprotonated species $(m / z, 773.53)$ are shown in Figure 3C. The measured $1 / \mathrm{K}_{0}$ values for individual PG (18:1(9Z)/18:1(9Z)) and PG (18:1(9E)/18:1(9E)) are 1.381 and 1.394 , respectively. The mixture of PG (18:1(9Z)/18:1(9Z)) and PG (18:1(9E)/18:1(9E)) confirms that the deprotonated species of each lipid can be well resolved $(r=1.1)$. Based on the lower mobility value, PG (18:1(9Z)/18:1(9Z)) takes on a more compact gas-phase structure than PG (18:1(9E)/18:1(9E)). Our results from both isomer pairs suggest that the lipids with $\mathrm{cis}$ double bonds have more compact structures than lipids with trans double bonds. These findings are aligned with existing literature, as cis double bonds are believed to introduce a bend or curl in in otherwise linear acyl chains.37

MALDI TIMS separations of double bond position and stereoisomers were also evaluated for cationic lipids. All positive ionization mode analysis was carried out on sodium-adducted PC standards.Figure 3D shows the extracted ion mobilograms of the $[\mathrm{M}+\mathrm{Na}]_{+}$ion $(\mathrm{m} / \mathrm{z}, 808.57)$ for PC $(18: 1(6 \mathrm{Z}) / 18: 1(6 \mathrm{Z}))$ and PC (18:1(9E)/18:1(9E)) that vary in both double bond position and double bond stereochemistry. The individual mobilograms of the sodiated species show that PC
$(18: 1(9 \mathrm{E}) / 18: 1(9 \mathrm{E}))\left(1 / \mathrm{K}_{0} 1.462\right)$ has a lower mobility value than PC (18:1(6Z)/18:1(6Z) $\left(1 / \mathrm{K}_{0} 1.468\right)$; the two standards are
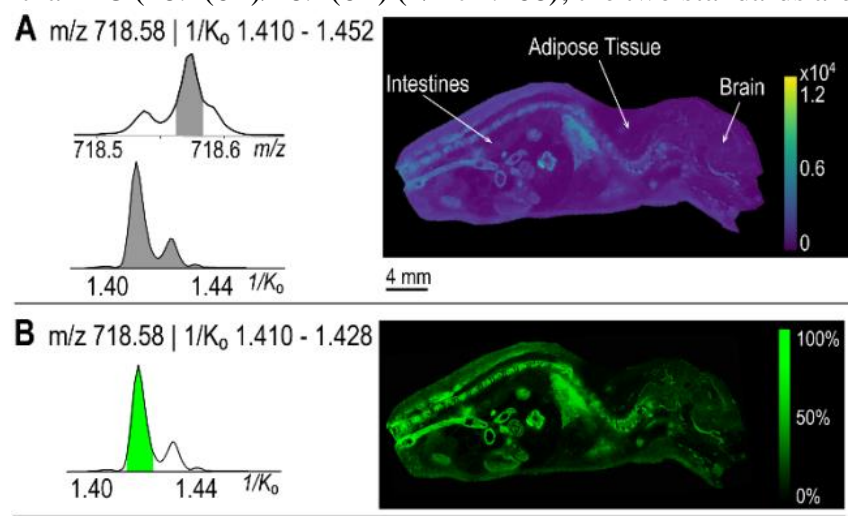

C $\mathrm{m} / \mathrm{z} 718.58 \mid 1 / \mathrm{K}_{0} 1.430-1.441$
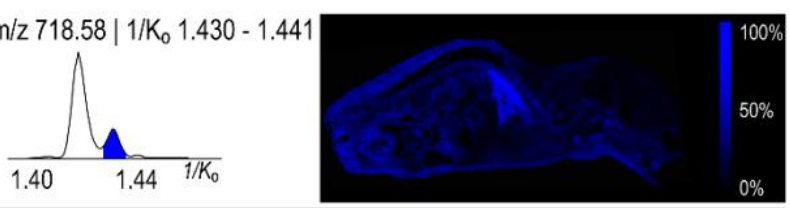

D $\mathrm{m} / \mathrm{z} 718.58 \mid 1 / \mathrm{K}_{0} 1.446-1.452$
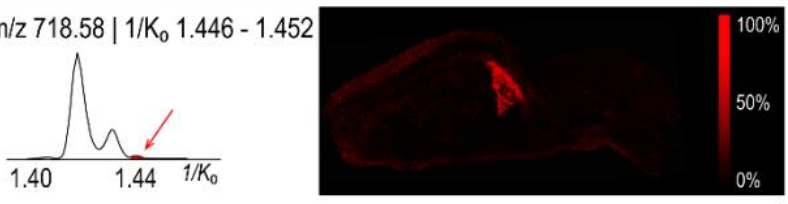

E $\mathrm{m} / \mathrm{z} 718.58 \mid 1 / \mathrm{K}_{0} 1.410-1.452$
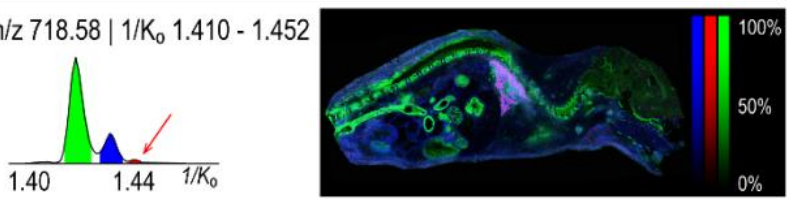

Figure 4: TIMS enables the separation of lipid isomers in whole-body mouse pup tissues. A composite image of all three peaks in the extracted ion mobilogram $\left(1 / \mathrm{K}_{0} 1.410-1.452\right)$ of $\mathrm{m} / \mathrm{z} 718.58$ is shown (A). Each panel highlights an ion image generated for three distinct mobility range $-1 / \mathrm{K}_{0} 1.410-1.428$ (B), $1.430-1.441$ (C), and 1.446 - 1.452 (D), and an overlay of all three mobility peaks (E). The three ions have different localizations across the tissue sample, however, the average ion image (A) is dominated by the spatial distributions of the highest intensity ion (B). The ions were putatively identified as $[\mathrm{CerP}(\mathrm{t} 40: 1)+\mathrm{H}]_{+},[\mathrm{PC}(\mathrm{O}-32: 1)+\mathrm{H}]_{+}$and $[\mathrm{PC}(\mathrm{P}-32: 0)+\mathrm{H}]_{+}$ ( $0.14 \mathrm{ppm}$ error) based on accurate mass alone.

not well resolved from a mixture of the standards $(r=0.52)$. Our results suggest that the $9 \mathrm{E}$ isomer results in a more compact structure than the $6 \mathrm{Z}$, which is consistent with previously published data suggesting that the trans orientation is more impacted by the sodium adduct, pulling it closer to headgroup, resulting in a more compact conformation than the $6 \mathrm{Z} .54$ To investigate the effect of double bond position alone, standard PC (18:1(6Z)/18:1(6Z)) was analyzed with PC (18:1(9Z)/18:1(9Z)) (Figure 3E). The individual extracted ion mobilograms $(m / z, 808.57)$ show that the $9 \mathrm{Z}$ isomer results in a smaller structure than the $6 \mathrm{Z}$, with $1 / \mathrm{K}_{0} 1.458$ and 1.468 , respectively. The mobilograms of the mixture shows separation of the two species with a resolution of 1.01. Our results indicate that the $9 \mathrm{Z}$ results in a more compact structure. This finding is also supported by previous literature stating that cis double bonds further from the carboxyl end curl the acyl chain more, causing smaller conformations.37 In addition to the aforementioned lipid isomers, PC (18:1(9E)/18:1(9E)) and PC 
(18:1(9Z)/18:1(9Z)) were analyzed to evaluate the separation of isomers with cis vs trans stereochemistry (Figure S4).

Lastly, mobility separations were performed on the $[\mathrm{M}+\mathrm{Na}]_{+}$ ion $(\mathrm{m} / \mathrm{z}$ 782.56) of PC (18:1(9Z)/16:0) and PC $(18: 1(11 Z) / 16: 0)$ (Figure 3F), isomers that vary only in the position of a single double bond. These lipid species are generally abundant in biological tissues and represent an interesting biological target. For instance, Paine et al. have demonstrated that although both PC (18:1(9Z)/16:0) and PC $(18: 1(11 Z) / 16: 0)$ are found in rat brain tissue, their relative abundances vary between white matter and gray matter.70 The individual mobilograms suggest that the $11 \mathrm{Z}\left(1 / \mathrm{K}_{0} 1.430\right)$ isomer has a more compact structure than the $9 \mathrm{Z}$ (1.436). Despite the difference in a single double bond location being very subtle, slight separation in the mobilogram was still observed $(\mathrm{r}=0.59)$.

\section{MALDI TIMS Separation and Localization of Lipid Isomers in Whole-body Mouse Pup Tissue}

MALDI TIMS-IMS was used to visualize the spatial distribution of lipid isomers in whole-body mouse pup tissue. From the average mass spectrum, an example of isomeric overlap is highlighted at $\mathrm{m} / z$ 718.58, where three distinct species are resolved in the extracted ion mobilogram (Figure 4A). An composite ion image for $m / z 718.58$ including all observed mobility peaks from $1 / \mathrm{K}_{0} 1.410-1.452$ (Figure 4A) was generated, followed by ion images for each ion mobility separated species (Figures 4B-4D). Each ion has a unique spatial distribution within the mouse pup tissue. The ion with $1 / \mathrm{K}_{0} 1.410-1.428$ (Figure 4B) is the highest intensity ion that localizes to the organs of the abdominal cavity, the spinal cord, and the brain with lower intensity. The ion with $1 / \mathrm{K}_{0} 1.430-$ 1.441 (Figure 4C) localizes primarily to the liver, to the connective tissue, and is completely absent in the brain. Lastly, the ion with mobility $1 / \mathrm{K}_{0} 1.446-1.452$ (Figure 4D) localizes to the liver and has very low intensity or is completely absent throughout the rest of the body. From the composite image, the highest intensity ion $\left(1 / \mathrm{K}_{0} 1.410-1.441\right)$ dominates the ion image, and the spatial distributions of the other two ions are lost. An overlay image of each of the ion mobility-resolved species is shown in Figure $\mathbf{4 E}$ highlighting the unique spatial distributions of each of these lipids. To determine if these ions were isobars or isomers, a serial section of the whole-body mouse pup was analyzed using ultra-high resolution FT-ICR MS (resolving power of $\sim 600,000$ at $\mathrm{m} / \mathrm{z}, 760$ ). The whole-body average FT-ICR spectrum suggests that the ions separated in mobility space are, in fact, isomers (Figure S5). An ion image was generated for $m / z$ 718.58, and the localizations match well to the MALDI TIMS composite ion image (Figure 4A). This data further confirms that the composite ion image of $\mathrm{m} / \mathrm{z}$ 718.58 is biased toward the most intense ion in the mass spectrum (Figure S5). The FT-ICR MS data was also used to assist in identifying the ions (Figure S5). From the FT-ICR mass spectrum, there are no nominally interfering peaks and no overlapping isotopic distribution could be detected. Based on mass accuracy alone the three isomeric species were tentatively identified as $[\mathrm{CerP}(\mathrm{t} 40: 1)+\mathrm{H}]_{+},[\mathrm{PC}(\mathrm{O}-32: 1)+\mathrm{H}]_{+}$and $[\mathrm{PC}(\mathrm{P}-$ $32: 0)+\mathrm{H}]_{+}(0.14$ ppm error $)$. This example highlights the utility of coupling TIMS with MALDI IMS.

\section{CONCLUSIONS}

This work has demonstrated the use of a MALDI timsTOF IMS for enhanced peak capacity and lipid isomer analysis. An additional 669 features were detected by incorporating TIMS, resulting in a $>250 \%$ increase in peak capacity. MALDI TIMS separation of lipid isomer standards, including $s n$-backbone isomers, acyl chain isomers, as well as double bond position and stereo- isomers was also demonstrated. Of note is the partial separation of PC (18:1(9Z)/16:0) and PC (18:1(11Z)/16:0). The two species vary in a single double bond location, and require high resolving powers $(>250)$ to separate in mixtures. Resolving these standards lays important groundwork for further MALDI TIMS-IMS experiments, as both species are generally abundant in biological tissues, but may differ in relative abundances. 70

Finally, in situ separation and imaging of lipid isomers with distinct spatial distributions was performed using whole-body mouse pup tissue. Gas-phase isobar and isomer separations confirm TIMS as a valuable tool that can bring new dimensions to IMS experiments. Lipid identification, however, remains a challenge, and TIMS data was supplemented with MALDI FTICR imaging to provide tentative lipid isomer identifications. Here we show that incorporating TIMS in a MALDI IMS workflow enhances the specificity of the experiment. Building on this, future multimodal studies that combine highperformance MALDI TIMS with advanced structural identification methods has the potential to further increase the depth of characterization of lipids in situ.

\section{ASSOCIATED CONTENT}

\section{Supporting Information}

Table S1. Experimental TIMS Parameters; Figure S1. Names, Structures, and Masses of lipid standards; Figure S2. Negative ionization mode mass spectra of standards; Figure S3. Positive ionization mode mass spectra of standards; Figure S4. Extracted ion mobilogram of PC (18:1(9Z)/18:1(9Z)) and PC (18:1(9E)/18:1(9E)); Figure S5. MALDI FT-ICR data.

\section{AUTHOR INFORMATION}

\author{
Corresponding Author \\ * Jeffrey M. Spraggins, Jeff.Spraggins@ vanderbilt.edu \\ Jeffrey M. Spraggins: 0000-0001-9198-5498
}

Katerina V. Djambazova:0000-0002-2680-9014

Dustin R. Klein: 0000-0001-7327-6479

Lukasz G. Migas: 0000-0002-1884-6405

Elizabeth K. Neumann: 0000-0002-6078-3321

Emilio S. Rivera: 0000-0003-3215-1092

Raf Van de Plas: 0000-0002-2232-7130

Richard M. Caprioli: 0000-0001-5859-3310

Author Contributions

All authors have given approval to the final version of the manuscript.

\section{ACKNOWLEDGMENT}

Support was provided by The National Science Foundation Major Research Instrument Program (CBET - 1828299 awarded to J.M.S. and R.M.C.) and The National Institutes of Health (NIH) National Institute of General Medical Sciences (P41 GM103391 awarded to R.M.C.). The 15T FT-ICR MS in the Mass Spectrometry Research 
Center at Vanderbilt University was acquired through the NIH Shared Instrumentation Grant Program (1S10OD012359). E.K.N. is supported by a National Institute of Environmental Health Sciences training grant (T32ES007028). The authors wish to thank Terry Dermody from the University of Pittsburgh for providing the mouse pup and Daniel Ryan for sample assistance.

\section{REFERENCES}

(1) Shevchenko, A.; Simons, K. Lipidomics: Coming to Grips with Lipid Diversity. Nat. Rev. Mol. Cell. Biol. 2010, 11 (8), 593-598. https://doi.org/10.1038/nrm2934.

(2) Liebisch, G.; Vizcaíno, J. A.; Köfeler, H.; Trötzmüller, M.; Griffiths, W. J.; Schmitz, G.; Spener, F.; Wakelam, M. J. O. Shorthand Notation for Lipid Structures Derived from Mass Spectrometry. J. Lipid Res. 2013, 54 (6), 1523-1530. https://doi.org/10.1194/jlr.M033506.

(3) Yang, K.; Han, X. Lipidomics: Techniques, Applications, and Outcomes Related to Biomedical Sciences. Trends Biochem. Sci. 2016, 41 (11), 954-969. https://doi.org/10.1016/j.tibs.2016.08.010.

(4) O'Donnell, V. B.; Ekroos, K.; Liebisch, G.; Wakelam, M. Lipidomics: Current State of the Art in a Fast Moving Field. Syst. $\begin{array}{llllll}\text { Biol. } & \text { Med. } & \mathbf{2 0 2 0}, & 12 & \text { (1), e1466 }\end{array}$ https://doi.org/10.1002/wsbm.1466.

(5) Rustam, Y. H.; Reid, G. E. Analytical Challenges and Recent Advances in Mass Spectrometry Based Lipidomics. Anal. Chem. American Chemical Society January 2, 2018, pp 374-397. https://doi.org/10.1021/acs.analchem.7b04836.

(6) Caprioli, R. M.; Farmer, T. B.; Gile, J. Molecular Imaging of Biological Samples: Localization of Peptides and Proteins Using MALDI-TOF MS. Anal. Chem. 1997, 69 (23), 4751-4760. https://doi.org/10.1021/AC970888I

(7) Angel, P. M.; Spraggins, J. M.; Baldwin, H. S.; Caprioli, R. Enhanced Sensitivity for High Spatial Resolution Lipid Analysis by Negative Ion Mode Matrix Assisted Laser Desorption Ionization Imaging Mass Spectrometry. Anal. Chem. 2012, 84 (3), 1557-1564. https://doi.org/10.1021/ac202383m.

(8) Berry, K. A. Z.; Hankin, J. A.; Barkley, R. M.; Spraggins, J. M.; Caprioli, R. M.; Murphy, R. C. MALDI Imaging of Lipid Biochemistry in Tissues by Mass Spectrometry. Chem. Rev. 2011, 111 (10), 6491. https://doi.org/10.1021/CR200280P.

(9) Cohen, L. H.; Gusev, A. I. Small Molecule Analysis by MALDI Mass Spectrometry. Anal. Bioanal. Chem. 2002, 373 (7), 571586. https://doi.org/10.1007/s00216-002-1321-z.

(10) Bhandari, D. R. a.; Schott, M.; Römpp, A.; Vilcinskas, A.; Spengler, B. Metabolite Localization by Atmospheric Pressure High-Resolution Scanning Microprobe Matrix-Assisted Laser Desorption/Ionization Mass Spectrometry Imaging in WholeBody Sections and Individual Organs of the Rove Beetle Paederus Riparius. Anal. Bioanal. Chem. 2015, 407 (8), 2189 2201. https://doi.org/10.1007/s00216-014-8327-1.

(11) Powers, T. W.; Neely, B. A.; Shao, Y.; Tang, H.; Troyer, D. A.; Mehta, A. S.; Haab, B. B.; Drake, R. R. MALDI Imaging Mass Spectrometry Profiling of N-Glycans in Formalin-Fixed Paraffin Embedded Clinical Tissue Blocks and Tissue Microarrays. PLoS $\begin{array}{lllll}\text { One 2014, } & 9 & \text { (9), } & \text { e106255. }\end{array}$ https://doi.org/10.1371/journal.pone.0106255.

(12) Drake, R. R.; Powers, T. W.; Norris-Caneda, K.; Mehta, A. S.; Angel, P. M. In Situ Imaging of N-Glycans by MALDI Imaging Mass Spectrometry of Fresh or Formalin-Fixed ParaffinEmbedded Tissue. Curr. Protoc. Protein Sci. 2018, 94 (1), e68. https://doi.org/10.1002/cpps.68.

(13) Schober, Y.; Guenther, S.; Spengler, B.; Römpp, A. HighResolution Matrix-Assisted Laser Desorption/Ionization Imaging of Tryptic Peptides from Tissue. Rapid Commun. Mass Spectrom. 2012, 26 (9), 1141-1146. https://doi.org/10.1002/rcm.6192.

(14) Prentice, B. M.; Ryan, D. J.; Van De Plas, R.; Caprioli, R. M.; Spraggins, J. M. Enhanced Ion Transmission Efficiency up to $\mathrm{m}$ / z 24000 for MALDI Protein Imaging Mass Spectrometry. Anal. Chem. 2018, $90 \quad$ (8), 5090-5099. https://doi.org/10.1021/acs.analchem.7b05105.

(15) Spraggins, J. M.; Caprioli, R. M. High-Speed MALDI-TOF Imaging Mass Spectrometry: Rapid Ion Image Acquisition and Considerations for Next Generation Instrumentation. J. Am. Soc
Mass Spectrom. 2011, $22 \quad$ (6), 1022-1031. https://doi.org/10.1007/s13361-011-0121-0.

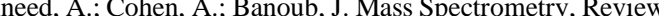
of the Basics: Electrospray, MALDI, and Commonly Used Mass Analyzers. Appl. Spectrosc. Rev. 2009, 44 (3), 210-230. https://doi.org/10.1080/05704920902717872.

(17) Smith, D. F.; Kiss, A.; Leach, F. E.; Robinson, E. W.; Paša-Tolić, L.; Heeren, R. M. A. High Mass Accuracy and High Mass Resolving Power FT-ICR Secondary Ion Mass Spectrometry for Biological Tissue Imaging. Anal. Bioanal. Chem. 2013, 405 (18), 6069-6076. https://doi.org/10.1007/s00216-013-7048-1.

(18) Kompauer, M.; Heiles, S.; Spengler, B. Atmospheric Pressure MALDI Mass Spectrometry Imaging of Tissues and Cells at 1.4Mm Lateral Resolution. Nat. Methods 2017, 14 (1), 90-96. https://doi.org/10.1038/nmeth.4071.

(19) Murphy, R. C.; Hankin, J. A.; Barkley, R. M. Imaging of Lipid Species by MALDI Mass Spectrometry. Journal of Lipid Research. American Society for Biochemistry and Molecular Biology April 1, 2009, pp S317-S322. https://doi.org/10.1194/jlr.R800051-JLR200.

(20) Tang, F.; Guo, C.; Ma, X.; Zhang, J.; Su, Y.; Tian, R.; Shi, R.; Xia, Y.; Wang, X.; Ouyang, Z. Rapid in Situ Profiling of Lipid $\mathrm{C}=\mathrm{C}$ Location Isomers in Tissue Using Ambient Mass Spectrometry with Photochemical Reactions. Anal. Chem. 2018, 90 (9),

$5612-5619$ https://doi.org/10.1021/acs.analchem.7b04675.

(21) Kozlowski, R. L.; Mitchell, T. W.; Blanksby, S. J. A Rapid Ambient Ionization-Mass Spectrometry Approach to Monitoring the Relative Abundance of Isomeric Glycerophospholipids. Sci. Rep. 2015, 5 (1), 1-9. https://doi.org/10.1038/srep09243.

(22) Klein, D. R.; Feider, C. L.; Garza, K. Y.; Lin, J. Q.; Eberlin, L. S.; Brodbelt, J. S. Desorption Electrospray Ionization Coupled with Ultraviolet Photodissociation for Characterization of Phospholipid Isomers in Tissue Sections. Anal. Chem. 2018, 90, 10. https://doi.org/10.1021/acs.analchem.8b03026.

(23) Porta Siegel, T.; Ekroos, K.; Ellis, S. R. Reshaping Lipid Biochemistry by Pushing Barriers in Structural Lipidomics. Angew. Chem. Int. Ed. 2019, 58 (20), 6492-6501. https://doi.org/10.1002/anie.201812698.

(24) Damen, C. W. N.; Isaac, G.; Langridge, J.; Hankemeier, T.; Vreeken, R. J. Enhanced Lipid Isomer Separation in Human Plasma Using Reversed-Phase UPLC with Ion-Mobility/HighResolution MS Detection. J. Lipid Res. 2014, 55 (8), 1772-1783. https://doi.org/10.1194/jlr.D047795.

(25) Lamont, L.; Baumert, M.; Ogrinc Potočnik, N.; Allen, M.; Vreeken, R.; Heeren, R. M. A.; Porta, T. Integration of Ion Mobility MSE after Fully Automated, Online, High-Resolution Liquid Extraction Surface Analysis Micro-Liquid Chromatography. Anal. Chem. 2017, 89 (20), 11143-11150. https://doi.org/10.1021/acs.analchem.7b03512.

(26) May, J. C.; Goodwin, C. R.; Lareau, N. M.; Leaptrot, K. L.; Morris, C. B.; Kurulugama, R. T.; Mordehai, A.; Klein, C.; Barry, W.; Darland, E.; et al. Conformational Ordering of Biomolecules in the Gas Phase: Nitrogen Collision Cross Sections Measured on a Prototype High Resolution Drift Tube Ion Mobility-Mass Spectrometer. Anal. Chem. 2014, 86 (4), 2107-2116. https://doi.org/10.1021/ac4038448.

(27) Valentine, S. J.; Koeniger, S. L.; Clemmer, D. E. A Split-Field Drift Tube for Separation and Efficient Fragmentation of Biomolecular Ions. Anal. Chem. 2003, 75 (22), 6202-6208. https://doi.org/10.1021/ac030111r.

(28) Zhong, Y.; Hyung, S.-J.; Ruotolo, B. T. Characterizing the Resolution and Accuracy of a Second-Generation TravelingWave Ion Mobility Separator for Biomolecular Ions. Analyst 2011, 136 (17), 3534. https://doi.org/10.1039/c0an00987c.

(29) Shvartsburg, A. A.; Smith, R. D. Fundamentals of Traveling Wave Ion Mobility Spectrometry. Anal. Chem. 2008, 80 (24), 9689-9699. https://doi.org/10.1021/ac8016295.

(30) Purves, R. W.; Guevremont, R. Electrospray Ionization HighField Asymmetric Waveform Ion Mobility Spectrometry-Mass Spectrometry. Int. J. Mass Spectrom. Ion Process. 1970, 52 (3), 2346-2357. https://doi.org/10.1021/ac981380y

(31) Kolakowski, B. M.; Mester, Z. Review of Applications of HighField Asymmetric Waveform Ion Mobility Spectrometry (FAIMS) and Differential Mobility Spectrometry (DMS). Analyst 
2007, 132 (9), 842. https://doi.org/10.1039/b706039d.

Guevremont, R. High-Field Asymmetric Waveform Ion Mobility Spectrometry: A New Tool for Mass Spectrometry. J. Chromatogr. A. 2004, $1058 \quad$ (1-2), 3-19. https://doi.org/10.1016/j.chroma.2004.08.119.

(33) Fernandez-Lima, F.; Kaplan, D. A.; Suetering, J.; Park, M. A. Gas-Phase Separation Using a Trapped Ion Mobility Spectrometer. Int. J. Ion Mobil. Spectrom. 2011, 14 (2-3). https://doi.org/10.1007/s12127-011-0067-8.

(34) Michelmann, K.; Silveira, J. A.; Ridgeway, M. E.; Park, M. A. Fundamentals of Trapped Ion Mobility Spectrometry. J. Am. Soc. Mass Spectrom. 2015, $26 \quad$ (1), 14-24. https://doi.org/10.1007/s13361-014-0999-4.

(35) Groessl, M.; Graf, S.; Knochenmuss, R. High Resolution Ion Mobility-Mass Spectrometry for Separation and Identification of Isomeric Lipids. Analyst. 2015, 140 (20), 6904-6911. https://doi.org/10.1039/C5AN00838G.

(36) Zheng, X.; Smith, R. D.; Baker, E. S. Recent Advances in Lipid Separations and Structural Elucidation Using Mass Spectrometry Combined with Ion Mobility Spectrometry, Ion-Molecule Reactions and Fragmentation Approaches. Curr. Opin. Chem. Biol. Elsevier Ltd February 1, 2018, pp 111-118. https://doi.org/10.1016/j.cbpa.2017.11.009.

(37) Kyle, J. E.; Zhang, X.; Weitz, K. K.; Monroe, M. E.; Ibrahim, Y. M.; Moore, R. J.; Cha, J.; Sun, X.; Lovelace, E. S.; Wagoner, J.; et al. Uncovering Biologically Significant Lipid Isomers with Liquid Chromatography, Ion Mobility Spectrometry and Mass Spectrometry. Analyst. 2016, 141 (5), 1649-1659. https://doi.org/10.1039/C5AN02062J

(38) McLean, J. A.; Ridenour, W. B.; Caprioli, R. M. Profiling and Imaging of Tissues by Imaging Ion Mobility-Mass Spectrometry. J. Mass Spectrom. 2007, 42 (8), 1099-1105. https://doi.org/10.1002/jms.1254.

(39) Škrášková, K.; Claude, E.; Jones, E. A.; Towers, M.; Ellis, S. R.; Heeren, R. M. A. Enhanced Capabilities for Imaging Gangliosides in Murine Brain with Matrix-Assisted Laser Desorption/Ionization and Desorption Electrospray Ionization Mass Spectrometry Coupled to Ion Mobility Separation. Methods. 2016, $104, \quad 69-78$. https://doi.org/10.1016/j.ymeth.2016.02.014

(40) Deng, L.; Ibrahim, Y. M.; Baker, E. S.; Aly, N. A.; Hamid, A. M Zhang, X.; Zheng, X.; Garimella, S. V. B.; Webb, I. K.; Prost, S. A.; et al. Ion Mobility Separations of Isomers Based upon Long Path Length Structures for Lossless Ion Manipulations Combined with Mass Spectrometry. ChemistrySelect 2016, 1 (10), 23962399. https://doi.org/10.1002/slct.201600460.

(41) Ibrahim, Y. M.; Hamid, A. M.; Deng, L.; Garimella, S. V. B.; Webb, I. K.; Baker, E. S.; Smith, R. D. New Frontiers for Mass Spectrometry Based upon Structures for Lossless Ion Manipulations. Analyst. 2017, 142 (7), 1010-1021. https://doi.org/10.1039/c7an00031f.

(42) Wojcik, R.; Webb, I. K.; Deng, L.; Garimella, S. V. B.; Prost, S A.; Ibrahim, Y. M.; Baker, E. S.; Smith, R. D. Lipid and Glycolipid Isomer Analyses Using Ultra-High Resolution Ion Mobility Spectrometry Separations. Int. J. Mol. Sci. 2017, 18 (1), 183. https://doi.org/10.3390/ijms18010183.

(43) Ma, X.; Chong, L.; Tian, R.; Shi, R.; Hu, T. Y.; Ouyang, Z.; Xia, Y. Identification and Quantitation of Lipid $\mathrm{C}=\mathrm{C}$ Location Isomers: A Shotgun Lipidomics Approach Enabled by Photochemical Reaction. Proc. Nat. Acad. Sci. 2016, 113 (10), 2573-2578. https://doi.org/10.1073/pnas.1523356113.

(44) Bowman, A. P.; Abzalimov, R. R.; Shvartsburg, A. A. Broad Separation of Isomeric Lipids by High-Resolution Differential Ion Mobility Spectrometry with Tandem Mass Spectrometry. J. Am. Soc. Mass Spectrom 2017, 28 (8), 1552-1561. https://doi.org/10.1007/s13361-017-1675-2

(45) Nagy, G.; Veličković, D.; Chu, R. K.; Carrell, A. A.; Weston, D. J.; Ibrahim, Y. M.; Anderton, C. R.; Smith, R. D. Towards Resolving the Spatial Metabolome with Unambiguous Molecular Annotations in Complex Biological Systems by Coupling Mass Spectrometry Imaging with Structures for Lossless Ion Manipulations. Chem. Commun. 2019, 55 (3), 306-309. https://doi.org/10.1039/c8cc07482h.

(46) Sans, M.; Feider, C. L.; Eberlin, L. S. Advances in Mass Spectrometry Imaging Coupled to Ion Mobility Spectrometry for
Enhanced Imaging of Biological Tissues. Curr. Opin. Chem. Biol. 2018, 42, 138-146. https://doi.org/10.1016/j.cbpa.2017.12.005. T. O. Separation and Classification of Lipids Using Differential Ion Mobility Spectrometry. J. Am. Soc. Mass Spectrom. 2011, 22 (7), 1146-1155. https://doi.org/10.1007/s13361-011-0114-z.

(48) Lintonen, T. P. I.; Baker, P. R. S.; Suoniemi, M.; Ubhi, B. K.; Koistinen, K. M.; Duchoslav, E.; Campbell, J. L.; Ekroos, K. Differential Mobility Spectrometry-Driven Shotgun Lipidomics. Anal. Chem. 2014, $86 \quad$ (19), 9662-9669. https://doi.org/10.1021/ac5021744.

(49) Feider, C. L.; Elizondo, N.; Eberlin, L. S. Ambient Ionization and FAIMS Mass Spectrometry for Enhanced Imaging of Multiply Charged Molecular Ions in Biological Tissues. Anal. Chem. 2016, 88 (23), 11533-11541. https://doi.org/10.1021/acs.analchem.6b02798.

(50) Spraggins, J. M.; Djambazova, K. V.; Rivera, E. S.; Migas, L. G.; Neumann, E. K.; Fuetterer, A.; Suetering, J.; Goedecke, N.; Ly, A.; Van De Plas, R.; et al. High-Performance Molecular Imaging with MALDI Trapped Ion-Mobility Time-of-Flight (TimsTOF) Mass Spectrometry. Anal. Chem. 2019, 91 (22), 14552-14560. https://doi.org/10.1021/acs.analchem.9b03612.

(51) Ridgeway, M. E.; Lubeck, M.; Jordens, J.; Mann, M.; Park, M. A. Trapped Ion Mobility Spectrometry: A Short Review. Int. J. Mass Spectrom. 2018, 425, 22-35. https://doi.org/10.1016/J.IJMS.2018.01.006.

(52) Hernandez, D. R.; DeBord, J. D.; Ridgeway, M. E.; Kaplan, D. A.; Park, M. A.; Fernandez-Lima, F. Ion Dynamics in a Trapped Ion Mobility Spectrometer. Analyst. 2014, 139 (8), 1913-1921. https://doi.org/10.1039/C3AN02174B.

(53) Silveira, J. A.; Ridgeway, M. E.; Park, M. A. High Resolution Trapped Ion Mobility Spectrometery of Peptides. Anal. Chem. 2014, 86 (12), 5624-5627. https://doi.org/10.1021/ac501261h.

(54) Fouque, K. J. D.; Ramirez, C. E.; Lewis, R. L.; Koelmel, J. P.; Garrett, T. J.; Yost, R. A.; Fernandez-Lima, F. Effective Liquid Chromatography-Trapped Ion Mobility Spectrometry-Mass Spectrometry Separation of Isomeric Lipid Species. Anal. Chem. 2019, $\quad 91 \quad$ (8), $\quad$ 5021-5027. https://doi.org/10.1021/acs.analchem.8b04979.

(55) Fu, T.; Oetjen, J.; Chapelle, M.; Verdu, A.; Szesny, M.; Chaumot, A.; Degli-Esposti, D.; Geffard, O.; Clément, Y.; Salvador, A.; et al. In Situ Isobaric Lipid Mapping by MALDI-Ion Mobility Separation-Mass Spectrometry Imaging. J. Mass Spectrom. 2020, e4531. https://doi.org/10.1002/jms.4531.

(56) Fahy, E.; Sud, M.; Cotter, D.; Subramaniam, S. LIPID MAPS Online Tools for Lipid Research. Nucleic Acids Res. 2007, 35. https://doi.org/10.1093/nar/gkm324.

(57) Fahy, E.; Subramaniam, S.; Murphy, R. C.; Nishijima, M.; Raetz, C. R. H.; Shimizu, T.; Spener, F.; Van Meer, G.; Wakelam, M. J. O.; Dennis, E. A. Update of the LIPID MAPS Comprehensive Classification System for Lipids. J. Lipid Res. 2009, 50 (SUPPL.), S9-S14. https://doi.org/10.1194/jlr.R800095-JLR200.

(58) Bielow, C.; Mastrobuoni, G.; Orioli, M.; Kempa, S. On Mass Ambiguities in High-Resolution Shotgun Lipidomics. Anal. Chem. 2017, 89 (5), 2986-2994. https://doi.org/10.1021/acs.analchem.6b04456.

(59) Wang, M.; Huang, Y.; Han, X. Accurate Mass Searching of Individual Lipid Species Candidates from High-Resolution Mass Spectra for Shotgun Lipidomics. Rapid Commun. Mass Spectrom. $\quad \mathbf{2 0 1 4}, \quad 28 \quad$ (20), 2201-2210. https://doi.org/10.1002/rcm.7015.

(60) Jeanne Dit Fouque, K.; Ramirez, C. E.; Lewis, R. L.; Koelmel, J. P.; Garrett, T. J.; Yost, R. A.; Fernandez-Lima, F. Effective Liquid Chromatography-Trapped Ion Mobility SpectrometryMass Spectrometry Separation of Isomeric Lipid Species. Anal. $\begin{array}{llll}\text { Chem. } & \text { 2019, } & 91 & \text { (8), }\end{array}$ https://doi.org/10.1021/acs.analchem.8b04979.

(61) Hankin, J. A.; Murphy, R. C.; Barkley, R. M.; Gijón, M. A. Ion Mobility and Tandem Mass Spectrometry of Phosphatidylglycerol and Bis(Monoacylglycerol) Phosphate (BMP). Int. J. Mass Spectrom. 2015, 378, 255-263. https://doi.org/10.1016/j.ijms.2014.08.026.

(62) Anderson, D. M. G.; Ablonczy, Z.; Koutalos, Y.; Hanneken, A. M.; Spraggins, J. M.; Calcutt, M. W.; Crouch, R. K.; Caprioli, R. M.; Schey, K. L. Bis(Monoacylglycero)Phosphate Lipids in the 
Retinal Pigment Epithelium Implicate Lysosomal/Endosomal Dysfunction in a Model of Stargardt Disease and Human Retinas. Sci. Rep. 2017, 7 (1), 17352. https://doi.org/10.1038/s41598-01717402-1.

(63) Akgoc, Z.; Sena-Esteves, M.; Martin, D. R.; Han, X.; D’Azzo, A.; Seyfried, T. N. Bis(Monoacylglycero)Phosphate: A Secondary Storage Lipid in the Gangliosidoses. J. Lipid Res. 2015, 56 (5), 1006-1013. https://doi.org/10.1194/jlr.M057851.

(64) Numata, M.; Chu, H. W.; Dakhama, A.; Voelker, D. R Pulmonary Surfactant Phosphatidylglycerol Inhibits Respiratory Syncytial Virus-Induced Inflammation and Infection. Proc. Nat Acad. Sci. 2010, $107 \quad$ (1), 320-325. https://doi.org/10.1073/pnas.0909361107.

anmey, P. A.; Kinnunen, P. K. J. Biophysical Properties of Lipids and Dynamic Membranes. Trends Cell. Biol. 2006, 16 (10), 538-546. https://doi.org/10.1016/j.tcb.2006.08.009.

(66) Sandra, K.; Sandra, P. Lipidomics from an Analytical Perspective. Curr. Opin. Chem. Biol. 2013, 17 (5), 847-853. https://doi.org/10.1016/j.cbpa.2013.06.010.

(67) Lewis, B. A.; Engelman, D. M. Lipid Bilayer Thickness Varies
Linearly with Acyl Chain Length in Fluid Phosphatidylcholine Vesicles. J. Mol. Biol. 1983, 166 (2), 211-217. https://doi.org/10.1016/S0022-2836(83)80007-2.

Mitchell, T. W.; Pham, H.; Thomas, M. C.; Blanksby, S. J. Identification of Double Bond Position in Lipids: From GC to OzID. J. Chromatogr. B. 2009, 877 (26), 2722-2735. https://doi.org/10.1016/j.jchromb.2009.01.017.

(69) Brown, S. H. J.; Mitchell, T. W.; Oakley, A. J.; Pham, H. T.; Blanksby, S. J. Time to Face the Fats: What Can Mass Spectrometry Reveal about the Structure of Lipids and Their Interactions with Proteins? Lipid-Protein Interactions. J. Am. Soc. Mass Spectrom. 2012, 23, 1441-1449. https://doi.org/10.1007/s13361-012-0410-2.

(70) Paine, M. R. L.; Poad, B. L. J.; Eijkel, G. B.; Marshall, D. L.; Blanksby, S. J.; Heeren, R. M. A.; Ellis, S. R. Mass Spectrometry Imaging with Isomeric Resolution Enabled by Ozone-Induced Dissociation. Angew. Chem. Int. Ed. 2018, 57 (33), 10530-10534. https://doi.org/10.1002/anie.201802937. 